\title{
Factor Analysis of Passengers' Satisfaction in Nigerian Airports
}

\author{
Sidiq Okwudili Ben \\ Department of Geography \\ College of Education Ikere, Ekiti, Nigeria \\ Email: sidiqoben@yahoo.com
}

\begin{abstract}
This study determined complex factors influencing passengers' satisfaction in Nigerian Airports. Theoretical evidence was examined and factor analysis was carried out to identify the main groups of factors affecting passengers' satisfaction at the Airport. Primary data was gathered from domestic air passengers with random and systemic sampling techniques. 7I.I percent of questionnaires were retrieved from respondents in Lagos, and 61.9 percent of questionnaires were retrieved from respondents in Abuja. The findings of the study show that the most important five factors affecting it are: courtesy of staff, availability of staff, effective way finding signs, availability of telecommunications, and cleanliness of restrooms. The results obtained from this study will help airport managers in the Nigeria to better serve their passengers through improved attitudes of airport staff and improved technologies.
\end{abstract}

Keywords: Airport development, customer satisfaction, factor analysis, Nigerian Airport

\section{Introduction}

Recently, global aviation industry is gaining more and more weight, what in turn significantly adds to national economies. It plays an important role in moving individuals and products locally or internationally. Plus, a new trend in shifting from stately to privately owned airports makes ground open for major transformation of the establishments. As a result, numerous innovations along with more consumer friendly approach lead passengers to higher rate the services they have experience with (Sergejs and Ksenija, 2015). Airports are enterprises that spin around in any country. Nigerian government realizes the importance of developing aviation industry.

The enterprise coordinated mutual efforts of numerous private and public organizations.In the given conditions, delivery of high quality services to passengers become the primary competitive advantage for the airport sustained growth and efficient operation of domestic air services (Arif, Gupta, \& Williams, 2013). Providing high quality services to passengers is one of the positive factors for attracting major air carriers to an air hub (Saha \& Theingi, 2009; Aksoy, Atilgan, \& Akinci, 2003 ).

This study proposed that the management at Nigerian Airports shift the focus of their planned activities more towards increasing the service quality. The resulting increased passenger satisfaction would favourably influence the competitive advantage of the airfield. Consequently, the retained and newly gained passenger traffic may attract new airlines, investment and greater share in the Nigerian aviation market. The aim of this study is to determine complex factors influencing passenger satisfaction in Nigerian domestic Airport.

\section{Literature Review}

Consumer satisfaction with service quality is a significant aspect that the airport's management must consider to generate competitiveness, increased income and sustainable growth (Fadare \& Adeniran, 2018). In current competitive environment, the high quality service and resulting increased consumer satisfaction create an important advantage of increased loyalty and positive word of mouth. It is generally believed that higher satisfaction with services can significantly boost customer loyalty and lead to repeated purchases (Dolnicar, Grabler, Grün, \& Kulnig, 20II). Thus customer satisfaction does have a positive outcome on company's profitability.

In order to reach the goal, airport managements need to recognize passenger expectations for services provided (Gilbert \& Wong, 2003). Service quality can be defined as a passenger overall impression of the efficiency of the company and its services (Johnston, 1995). Thus the understanding of what passengers expect is the most vital step in delivering and defining the highquality service. Service quality evaluation by customers is one of the best approaches to determine their perception and expectations (Adikariwattage, De Barros, Wirasinghe, \& Ruwanpura, 2012). Fulfilled or even surpassed expectations of passengers lead to their satisfaction with airport's provided services (Sergejs and Ksenija, 2015).

Passenger satisfaction can be defined as a judgment made on the basis of a specific service encounter (Archana $\&$ Subha, 2012). Passenger satisfaction with services arises when an organization can provide its customers with benefits that exceed their original expectations, and this is perceived as value-added. Airport terminal experience is something special for 
passengers, as they have a variety of choices of services to select from for example, duty free or regular shopping, prayer rooms, numerous eateries, museums, club-rooms, information and transfer desks, smoking areas, security, airline offices, support for passengers with disabilities, restrooms, walkways, gates, all types of transportation and parking areas (Sergejs and Ksenija, 20I5). The airport services may meet the needs of the passengers partly, completely or exceedingly. Therefore, it is expected that airport administrations are continuously seeking for new services, developments and innovations to differentiate themselves from the competing airports. There is a variety of options to expand services, and doing that better serve existing, but attract more passengers. Airport services, like conference facilities, spa centres, sleep-boxes, exhibitions or even casinos can be presently found in variety of its areas. Present-day business traveller with the need to organize a corporate meeting may prefer to choose an airport offering a comprehensive package of a conference business centre, hotel rooms and eateries. Having exceptional experience could even make the passenger to pick a particular airport among the rest for the leisure purposes or even as a preferred point for a transfer in future. However, should in case the passenger is not satisfied with the time spent at a particular airport, for instance due to lack of choice or quality of services, the passenger may possibly reconsider his decision to arrive there in favour of another airport with better suitable profile. Plus, "an intention to return to the same airport" and "readiness to recommend it to others" positively affect airport's development (Fernandes \& Pacheco, 2002). Thus, the excellent passenger satisfaction is one of the best assets for airport business in competitive environment.

Marketing theory suggests that increasing customer loyalty and its retention is a chief key to the ability of a company to generate profit (Gandomi \& Zolfaghar, 20I3). Recognition of the determinants affecting passenger satisfaction and a correlation between the one and loyalty are of utmost importance. There are many factors that can help an airport to form its customer base, where passengers' satisfaction can become the determining factor in evaluation of achievements of an entire operation. Airport passenger satisfaction has been studied by many researchers around the world for decades. Studies related to the service quality and customer satisfaction in the given field have been growing an interest for almost a decade. A number of researchers have solely elaborated on related theories (Correia \& Wirasinghe, 2007), methods (De Nicola, Gitto, \& Mancuso, 20I3) and models (Lubbe, Douglas, \& Zambellis, 20I I) related to service quality throughout the industry (Arblaster, 20I4).

Most of previously conducted studies rely mainly on passenger satisfaction with airport services (Norazah Mohd, 2014) and conducted analyses of empirical data on the matter (Pabedinskaite \& Akstinaité, 20I4) with an accent on the effect of quality of services on passengers consecutive behaviour (Wittman, 2014; Steven, Dong \& Dresner, 2012; Park, 2007). Some researchers have assumed that the measurement of consumer satisfaction should be used in combination with the assess ment of necessity level of services and its perceived value. This is due to the chance, the latter might come out to be more accurate predicator of returning intentions (loyalty) than quality and satisfaction (Park, Robertson \& Wu, 2004; Chen, 2008). Hence, perceived value, service quality and general satisfaction with services, all seem to be good predictors of passengers returning intentions (Petrick \& Backman, 2002). Although, the specific relationship between variables still remains unclear, this study is tailored to examine the factors affecting passenger satisfaction with Nigerian domestic Airports services.

One of the major steps to conducting the survey of passengers was to determine the most applicable factors influencing the overall perception of airport functioning by a passenger. For this reason, the SKYTRAX Airports indicators were examined by questionnaire, where the matters related to the airport service evaluation process were revived. This survey conveys the factors concerning both the objective and subjective criteria to evaluate the overall quality of airport operations.

It is possible to measure objective criteria, like waiting time, walking distance or punctuality, in two ways. The first step is to employ real experimental measurements of these criteria for instance minutes or metres that were gained from the monitoring systems or observation. And the second one is about the passenger perception of evaluation or weighting the criteria. For instance, the researchers would be interested in how passengers evaluate a distance between two points at the airport on a scale ranging from short to very long. The measurement of subjective criteria, like evaluation of overall attitude of the check-in staff or airport security, cleanliness and comfort of restrooms or Wi-Fi coverage, can be evaluated in terms of the passenger perception only. The Airports Council International questionnaire contains 5I exceptionally detailed criteria for evaluation. However Correia Wirasinghe and De Barros (2008) stressed seven common factors which are waiting time; processing time; walking time; walking distance; level changes; orientation/information; space availability for passengers.

The authors consider these factors being important dimensions, but insufficient to be used as variables for the evaluation of passenger satisfaction with their experience. Another attempt to classify the factors influencing passenger satisfaction has been made by De Barros, Somasundaraswaran and Wirasinghe (2007). The researchers have created a questionnaire in order to evaluate passengers' subjective experience. Commuters were asked to rate their experience accordingly to 22 offered factors that were previously classified by authors into six categories: which are transit; rest rooms; restaurants $\&$ bars; duty free shops; security; other facilities. The passengers were also asked to rate their overall experience at the airport. For this reason, the authors considered this approach more practical for the investigation of problem related factors.

After reviewing various studies, thirty-nine (39) consumer satisfaction evaluating factors were extracted. Furthermore, it was suggested that these specific factors could be generalized and united into broader categories, and the passengers' satisfaction survey were conducted, where the given number of airport operations influencing factors were included into question statements. The task was to reveal the passengers' perception on general experience and specific factors. The received results created the 
needed pool of data for the conducting of factor analysis, which in its turn helped to find the complex factors. The results of this study could assist airport managers to better serve their passengers, develop and monitor service quality and to gain the highest level of customer satisfaction.

\section{Methodology}

This study adopted the use of factor analysis relying on primary data. Data was obtained from passengers of eight airlines in Lagos and Abuja domestic Airports. The populations for this study are domestic air passengers in Nigeria since the study focused on demand for domestic air travel passenger in Lagos and Abuja Airports. To specifically put it, the population was those volumes of passengers using the two airports being studied within the study period when data gathering occurred. We were at the two airports for one week each. To get the target population for the one week period at each airport we use the average passenger volume per annum for domestic passenger movement from a ten year period. Research population for Murtala Muhammed Airport 2 (MMA2), Lagos is 3,632,620 per annum. Research population for Nnamdi Azikiwe Domestic Airport (NADA), Abuja is 3,273,493 per annum. The weekly population was estimated to be 75,680 and 68,198 for Lagos and Abuja respectively.

To determine the sample size of the study, the some judgments were made by reducing the mean year estimate data to the period of one weekly estimate. Also IO percent of one weekly estimate was chosen because of time limitation and the readiness of respondents to fill the questionnaires. This is shown in Table I.

Table I: Sample size determination of the study

\begin{tabular}{lllll}
\hline AIRPORT & $\begin{array}{l}\text { Estimated } \\
\text { Yearly Mean }\end{array}$ & $\begin{array}{l}\text { Estimated } \\
\text { Monthly mean }\end{array}$ & $\begin{array}{l}\text { Estimated One } \\
\text { weekly mean }\end{array}$ & $\begin{array}{l}\text { Sample size (being I0 percent of the } \\
\text { weekly mean) }\end{array}$ \\
\hline Lagos & $3,632,620$ & 302718 & 75679.5 & 757 \\
\hline Abuja & $3,273,493$ & 272791 & 68197.75 & 682 \\
\hline TOTAL & & & I439 \\
\hline
\end{tabular}

Source: Sidiq (2018)

The sample size was 1439 respondents.

The technique of sampling the passengers for primary data collection was both random and systemic sampling techniques because the population is large and selection were done according to a random starting point and at a fixed periodic interval. The weekly population estimates are 75,680 and 68,198 for Lagos and Abuja respectively and going by a I0 percent sampling size of the weekly population, a total of 108 passengers/respondents were targeted daily between the hours of 7 am to $7 \mathrm{pm}$ with an average of 9 persons per hour the study in MMA2. While for NADA 97passengers/respondents were targeted for the same period and an average of 8 persons per hour. It meant that an average of 6.7 minutes was spent with each respondent in Lagos and 7.5 minutes with Abuja respondents.

For model specification, Factor analysis is a statistical method used to reduce a large cloud of data to a little amount of complex factors (in this case complex factors reflecting on passenger satisfaction), to detect the attendance of substantial patterns among the initial variables (Black, Hair, Tatham, Babin, \& Anderson, 2007) and to elicit the main factors representing relationships between the sets of many interrelated variables (Warne \& Larsen, 20I4). If the observed variables are $\mathrm{X}_{\mathrm{I}}, \mathrm{X}_{2} \ldots$. $\mathrm{X}_{\mathrm{n}}$, the common factors are $\mathrm{F}_{1}, \mathrm{~F}_{2} \ldots \mathrm{F}_{\mathrm{m}}$ and the unique factors are $\mathrm{U}_{\mathrm{I}}, \mathrm{U}_{2} \ldots \mathrm{U}_{\mathrm{n}}$, the variables may be expressed as linear functions of the factors:

$\mathrm{X}_{\mathrm{I}}=\mathrm{aII}_{11} \mathrm{~F}_{\mathrm{I}}+\mathrm{a}_{2} \mathrm{~F}_{2}+\mathrm{al}_{3} \mathrm{~F}_{3}+\ldots+\mathrm{aIm}_{\mathrm{m}} \mathrm{F}_{\mathrm{m}}+\mathrm{a}_{\mathrm{I}} \mathrm{U}_{\mathrm{I}}$

$\mathrm{X}_{2}=\mathrm{a}_{21} \mathrm{~F}_{\mathrm{I}}+\mathrm{a}_{22} \mathrm{~F}_{2}+\mathrm{a}_{23} \mathrm{~F}_{3}+\ldots+\mathrm{a}_{2 \mathrm{~m}} \mathrm{~F}_{\mathrm{m}}+\mathrm{a}_{2} \mathrm{U}_{2}$

$\ldots$

$\mathrm{X}_{\mathrm{n}}=\mathrm{ann}_{\mathrm{n}} \mathrm{F}_{1}+\mathrm{ann}_{2} \mathrm{~F}_{2}+\mathrm{ann}_{3} \mathrm{~F}_{3}+\ldots+\mathrm{annm}_{\mathrm{mm}} \mathrm{F}_{\mathrm{m}}+\mathrm{ann}_{\mathrm{n}} \mathrm{U}_{\mathrm{n}}$

Each of these equations is a regression equation; factor analysis seeks to find the coefficients a al, al2 ... anm which best reproduce the observed variables from the factors. The coefficients a 11 , al2 $\ldots$ anm are weighted in the same way as regression coefficients because of some reasons: the variables are standardised, and the constant is zero, therefore it is not shown.

An example is the coefficient an that shows the effect on variable $\mathrm{X}_{\mathrm{I}}$ of a one-unit increase in $\mathrm{F}_{\mathrm{I}}$. In factor analysis, the coefficients are called loadings (a variable is said to load on a factor) and, when the factors are uncorrelated, they also show the correlation between each variable and a given factor. In the model above, a 1 is the loading for variable $\mathrm{X}_{\mathrm{I}}$ on $\mathrm{F}_{1}$, a23 is the loading for variable $\mathrm{X}_{2}$ on $\mathrm{F}_{3}$, etc. When the coefficients are uncorrelated, that means the factors are uncorrelated, and the sum of the squares of the loadings for variable $\mathrm{X}_{\mathrm{I}}$, namely ain2 + a122 $+\ldots+$ a132, shows the proportion of the variance of variable $\mathrm{X}_{\mathrm{I}}$ which is accounted for by the common factors. This is called the communality. The larger the communality for each variable, the more 
successful a factor analysis solution is. Also, the greater the discrepancy, the less successful the factor solution will be in preserving the information in the original correlation matrix.

\section{Results and Discussion}

From the questionnaire described above, a list containing thirty-nine (39) initial factors concerning passenger satisfaction with airport services was developed. The factors influencing customer satisfaction were selected on the basis of the named aspects. The survey questions were built by the researcher in such a way, that the obtained data could be further used whilst applying the factor analysis and getting the number of complex factors as a result. The respondents were offered to evaluate each of 39 factors that influence their satisfaction with airport services. Ten-point scale was used for evaluating the factors measured, where "I" meant that the factor did not affect the satisfaction level at all, but "I0" that the factor extremely affected their satisfaction level. According to a number of scientific studies, the I0-point scale was widely recognized as the most suitable for researching customer satisfaction, expectations or evaluations (Coelho \& Esteves, 2007; Hill, Roche, \& Allen, 2007).

In order to evaluate the strength of the relationship between variables, correlation coefficient was adopted, which additionally allowed manipulating with different data types simultaneously. Then, factor analysis was carried out by the principal component analysis but factor rotation implemented by Varimax method with Kaiser Normalization. The Kaiser- Meyer-Olkin (KMO) test was performed to confirm the sampling adequacy for the implementation of factor analysis.

The factor loadings performed are the correlations between the variables and factors. The practical meaning of a complex factor can be produced by combining those variables that have relatively high factor loadings after implementing the principal component factor analysis by Varimax rotation. The mentioned variables are loaded maximally to only one complex factor and minimally to the rest of complex factors. The produced six complex factors are the key dimensions of all 39 factors adapted from SKYTRAX. From the result of complex factors, five most significant passenger satisfaction factors were produced by factor analysis. They are as follows: courtesy of staff, availability of staff, effective way finding signs, availability of telecommunications, and cleanliness of restrooms.

Factor analysis was employed to identify the most important complex factors that could influence passenger satisfaction. The results can be used by the administration of Nigerian Airports with the purpose of increasing passenger satisfaction and loyalty, as well as avoiding negative reputation. The significance level barrier in this study followed the general level for statistical significance of 0.05 .

\section{Conclusion}

This study concentrated on the factors revealing passenger satisfaction at Nigerian domestic Airport. Factor analysis was employed to obtain empirical evidence about passenger satisfaction at Nigerian domestic Airport considering Lagos and Abuja. The findings of the study suggest that the most important five factors affecting passenger satisfaction with Nigerian domestic airport are courtesy of staff, availability of staff, effective way finding signs, availability of telecommunications, and cleanlines s of restrooms

\section{References}

Adikariwattage, V., De Barros, A. G., Wirasinghe, S. C., \& Ruwanpura, J. (2012). Airport classification criteria based on passenger characteristics and terminal size. Journal of Air Transport Management, 24, 36-4I. http://dx.doi.org/I0.1016/j.jairtraman.2012.06.004

Aksoy, S., Atilgan, E., Akinci, S. (2003). Airline services marketing by domestic and foreign firms: differences from the customers' viewpoint. Journal of Air Transport Management, 9, 343-35I.

Arblaster, M. (20I4). The design of light-handed regulation of airports: Lessons from experience in Australia and New Zealand. Journal of Air Transport Management, 38, 27-35.

Archana, R., \& Subha, M. V. (2012). A study on service quality and passenger satisfaction on Indian airlines. International Journal of Multidisciplinary Research, 2 (2), 50-63.

Arif, M., Gupta, A., \& Williams A. (2013). Customer service in the aviation industry - An exploratory analysis of UAE airports. Journal of Air Transport Management, 32, I-7.

Black, W. C., Hair, F. J., Tatham, R. L., Babin, B., \& Anderson, R. E. (2007). Multivariate data analysis. Upper Saddle River, NJ: Prentice-Hall.

Chen, C-F. (2008). Investigating structural relationships between service quality, perceived value, satisfaction, and behavioral intentions for air passengers: Evidence from Taiwan. Transportation Research Part A, 42, 709-717. http://dx.doi.org/10.1016/j.tra.2008.01.007

Coelho, S. P., \& Esteves, P. S. (2007). The choice between a five-point and a ten-point scale in the framework of customer satisfaction measurement. International Journal of Market Research, 49(3), 313- 339.

Correia, A. R., Wirasinghe, S. C., \& De Barros, A. G. (2008). Overall level of service measures for airport passenger terminals. Transportation Research Part A, 42, 330-346. 
Correia, R. A., \& Wirasinghe, S. C. (2007). Development of level of service standards for airport facilities: Application to Sao Paulo International Airport. Journal of Air Transport Management, 13 (2), 97-I03. http://dx.doi.org/I0.1016/j.jairtraman.2006.10.002

De Barros, A. G., Somasundaraswaran, A. K., \& Wirasinghe, S. C. (2007). Evaluation of level of service for transfer passengers at airports. Journal of Air Transport Management, 13, 293-298.

De Nicola, A., Gitto, S., \& Mancuso, P. (2013). Airport quality and productivity changes: A Malmquist index decomposition assessment. Transportation Research Part E: Logistics and Transportation Review, 58, 67-75. http://dx.doi.org/I0.I016/j.tre.2013.07.00I

Dolnicar, S., Grabler, K., Grün, B., \& Kulnig, A. (20II). Key drivers of airline loyalty. Tourism Management, 32 (5), I020I026. http://dx.doi.org/I0.I0I6/j.tourman.20I0.08.0I4

Fadare, S. O, \& Adeniran, A. O. (2018). Comparative Analysis of Public Operated Airport Terminal and Concessioned Airport Terminal in Lagos, Nigeria. Discovery, 54(272), 304-3I8

Fernandes, E., \& Pacheco, R. R. (2002). Efficient use of airport capacity. Transportation Research Part A, 36 (3), $225-238$. http://dx.doi.org/I0.1016/s0965-8564(00)00046-x

Gandomi, A., \& Zolfaghari, S. (2013). Profitability of loyalty reward programs: An analytical investigation. Omega, 4I (4), 797-807. http://dx.doi.org/I0.1016/j.omega.2012.10.003

Gilbert, D., \& Wong, R. (2003). Passenger expectations and airlines services: a Hong Kong based study. Tourism Management, 24, 5I9-532. http://dx.doi.org/I0.I0I6/S026I-5I77(03)00002-5

Hill, N., Roche, G., \& Allen, R. (2007). Customer Satisfaction: The Customer Experience Through the Customer's Eyes. The Leadership Factor, 125 p.

Johnston, R. (1995). The determinants of service quality: satisfiers and dissatisfiers. International Joumal of Service Industry Management, 6 (5), 53-7I.

Lubbe, B., Douglas, A., \& Zambellis, J. (20II). An application of the airport service quality model in South Africa. Journal of Air Transport Management, 17 (4), 224-227.

Norazah Mohd, S. (20I4). Passenger satisfaction with airline service quality in Malaysia: A structural equation modeling approach. Research in Transportation Business \& Management, In Press, Corrected Proof.

Pabedinskaité, A., \& Akstinaitè, V. (20I4). Evaluation of the Airport Service Quality. Procedia - Social and Behavioral Sciences, II0, 398-409.

Park, J., Robertson, R., \& Wu, C. (2004). The effect of airline service quality on passengers' behavioral intentions: a Korean case study. Journal of Air Transport Management, I0, 435-439.

Park, J-W. (2007). Passenger perceptions of service quality: Korean and Australian case studies. Journal of Air Transport Management, 13 (4), 238-242.

Petrick, J. F., \& Backman, S. J. (2002). An examination of the construct of perceived value for the prediction of golf travelers' intentions to revisit. Journal of Travel Research, 4I (I), 38-45.

Saha, G.C., \& Theingi, A. (2009). Service quality, satisfaction, and behavioural intentions: A study of low-cost airline carriers in Thailand. Managerial Service Quality, I9 (3), 350-372.

Sergejs, P.,\& Ksenija, I. (2015). Factor analysis of passengers' satisfaction at RIGA International Airport. Economics and Business, 27, 46-52. doi: I0.1515/eb-2015-0007.

Steven, A.B., Dong, Y., \& Dresner, M. (2012). Linkages between customer service, customer satisfaction and performance in the airline industry: investigation of non-linearities and moderating effects. Transportation Research Part E: Logistics and Transportation Review, 48 (4), 743-754.

Warne, R. T., \& Larsen, R. (20I4). Evaluating a proposed modification of the Guttman rule for determining the number of factors in an exploratory factor analysis. Psychological Test and Assessment Modeling, 56, 104-123.

Wittman, M. D. (20I4). Are low-cost carrier passengers less likely to complain about service quality? Journal of Air Transport Management, 35, 64-7I.

\section{Copyrights}

Copyright for this article is retained by the author(s), with first publication rights granted to the journal. This is an open-access article distributed under the terms and conditions of the Creative Commons Attribution license (http://creativecommons.org/licenses/by/4.0/). 